\title{
Vibrio alginolyticus Mutants Resistant to Phenamil, a Specific Inhibitor of the Sodium-driven Flagellar Motor
}

\section{Seiji Kojima', Tatsuo Atsumi², Kazumasa Muramoto', Seishi Kudo ${ }^{3}$ Ikuro Kawagishi' and Michio Homma ${ }^{1 *}$}

${ }^{1}$ Division of Biological

Science Graduate School of

Science Nagoya University

Chikusa-ku, Nagoya 464-01

Japan

${ }^{2}$ Department of Physics

Suzuka College of

Technology, Shiroko-cho

Suzuka, Mie 510-02, Japan

${ }^{3}$ Tsukuba Research

Laboratory, Yaskawa Electric

Corporation, 5-9-10 Tokodai

Tsukuba, 300-26, Japan

\begin{abstract}
The polar flagella of Vibrio alginolyticus are driven by sodium motive force and those motors are specifically and strongly inhibited by phenamil, an amiloride analog that is thought to interact with a sodium channel of the flagellar motor. To study the sodium ion coupling site, we isolated motility mutants resistant to phenamil and named the phenotype $\mathrm{Mpa}^{\mathrm{r}}$ for motility resistant to phenamil. The motility of the wild-type $\left(\mathrm{Mpa}^{\mathrm{s}}\right)$ was inhibited by $50 \mu \mathrm{M}$ phenamil, whereas $\mathrm{Mpa}^{\mathrm{r}}$ strains were still motile in the presence of $200 \mu \mathrm{M}$ phenamil. The $K_{i}$ value for phenamil in the $\mathrm{Mpa}^{\mathrm{r}}$ strain was estimated to be five times larger than that in the $\mathrm{Mpa}^{\mathrm{s}}$ strain. However, the sensitivities to amiloride or benzamil, another amiloride analog, were not distinctly changed in the $\mathrm{Mpa}^{\mathrm{r}}$ strain. The rotation rate of the wild-type $\mathrm{Na}^{+}$-driven motor fluctuates greatly in the presence of phenamil, which can be explained in terms of a relatively slow dissociation rate of phenamil from the motor. We therefore studied the stability of the rotation of the $\mathrm{Mpa}^{\mathrm{r}}$ and $\mathrm{Mpa}^{\mathrm{s}}$ motors by phenamil. The speed fluctuations of the $\mathrm{Mpa}^{\mathrm{r}}$ motors were distinctly reduced relative to the $\mathrm{Mpa}^{\mathrm{s}}$ motors. The steadier rotation of the $\mathrm{Mpa}^{\mathrm{r}}$ motors can be explained by an increase in the phenamil dissociation rate from a sodium channel of the motor, which suggests that a phenamil-specific binding site of the motor is mutated in the $\mathrm{Mpa}^{\mathrm{r}}$ strain.
\end{abstract}

(C) 1997 Academic Press Limited

Keywords: flagella; amiloride; Vibrio; motor; sodium-motive force

\section{Introduction}

Bacterial flagellar motors are molecular machines powered by the electrochemical potential gradient of specific ions across the membrane (Blair, 1995; Imae \& Atsumi, 1989). The flagellar motors can be classified by coupling ion: some are $\mathrm{H}^{+}$-driven and some are $\mathrm{Na}^{+}$-driven. The motor contains several independently functioning force-generating units, which should interact with coupling ion at the external surface of the cytoplasmic membrane and function as ion channels. It has been estimated that the $\mathrm{H}^{+}$-driven motor of Escherichia coli and the $\mathrm{Na}^{+}-$ driven motor of an alkalophilic Bacillus have eight

Present address: K. Muramoto, Department of Molecular Biophysics and Biochemistry, Yale University, New Haven, CT 06520-8114, USA.

Abbreviations used: Pof, polar flagellum; Laf, lateral flagellum; $\mathrm{Mpa}^{\mathrm{r}}$, motility resistant to phenamil; LDM, laser-dark field microscopy. and five to nine force-generating units, respectively (Block \& Berg, 1984; Blair \& Berg, 1988; Muramoto et al., 1994). For studies of the flagellar motor, the $\mathrm{Na}^{+}$-driven type presents certain advantages: the sodium motive force can be easily changed by the $\mathrm{Na}^{+}$concentration of the medium and the motor rotation can be specifically and competitively inhibited by amiloride (Sugiyama et al., 1988), which are potent inhibitors of $\mathrm{Na}^{+}$channel, $\mathrm{Na}^{+} / \mathrm{H}^{+}$ exchangers, and $\mathrm{Na}^{+} / \mathrm{Ca}^{2+}$ exchangers (Cragoe et al., 1992). An amiloride analog, phenamil, whose inhibition is non-competitive with $\mathrm{Na}^{+}$, is more potent than amiloride without affecting cell growth of alkalophiles (Atsumi et al., 1990; Sugiyama et al., 1988). The inhibitors are thought to interact with the force-generating units of the motors (Sugiyama et al., 1988; Atsumi et al., 1990; Muramoto et al., 1994, 1995).

Some marine Vibrio species have both types of motors in one cell. A single polar flagellum (Pof) rotates by a $\mathrm{Na}^{+}$-driven motor and multiple lateral 
flagella (Laf) rotate by $\mathrm{H}^{+}$-driven motors (Atsumi et al., 1992a; Kawagishi et al., 1995). The polar flagella work better for swimming in a low-viscosity environment than the lateral flagella (Atsumi et al., 1996). The restriction of the function of the polar flagellum appears to trigger the expression of lateral flagella (Kawagishi et al., 1996; McCarter et al., 1988). The polar flagella are covered with a sheath that is contiguous with the outer membrane (Follett \& Gordon, 1963; Allen \& Baumann, 1971) and the single filament is easily observed under the dark-field microscope.

The high-speed rotation of flagella has been analyzed by laser-dark field microscopy (LDM; Kudo et al., 1990; Kami-ike et al., 1991). Using this system, it was shown that the rotation of polar flagella was very fast in $V$. alginolyticus; the speeds of 600 r.p.s. were observed in the presence of $50 \mathrm{mM} \mathrm{NaCl}$ at room temperature, and surprisingly, the speeds increase up to 1700 r.p.s. in the presence of $300 \mathrm{mM} \mathrm{NaCl}$ at $35^{\circ} \mathrm{C}$ (Magariyama et al., 1994, 1995; Muramoto et al., 1995). It was also shown that the rotation of this motor was stable at high speed (Muramoto et al., 1995). The standard deviation of the rotation period was only $7 \%$ to $16 \%$ of the average rotation period in polar flagella of $V$. alginolyticus. When the rotation rate was reduced by decreasing external concentration of $\mathrm{NaCl}$ or adding amiloride or carbonylcyanide $m$ chlorophenylhydrazone (CCCP), the motor rotated smoothly. On the other hand, we found that the polar flagella showed remarkably larger speed fluctuations when the rotation rate was reduced by phenamil (Muramoto et al., 1996). The speed fluctuations induced by phenamil can be explained by the slow dissociation rate of the inhibitor from the force-generating unit.

To identify the force-generating units and investigate the sodium ion coupling site of the motor, it would be useful to identify the target of amiloride and its analogs in the flagellar motor. In this work, we synthesized phenamil, which had not been commercially available, isolated $V$. alginolyticus motility mutants resistant to phenamil and characterized the mutants with respect to the effect of phenamil on the rotation of the motor.

\section{Results}

\section{Isolation of motility mutants resistant to phenamil}

We tried to isolate mutants whose flagellar motors could function in the presence of amiloride or its more potent analogs, phenamil and benzamil. Experiments using amiloride or benzamil, which are commercially available, were not successful because their effects seem to be weak in the growth medium of $V$. alginolyticus whose ionic strength and $\mathrm{Na}^{+}$concentration are high (Atsumi et al., 1992b). Phenamil, which is known to be the most potent inhibitor of $\mathrm{Na}^{+}$-driven motors was then synthesized by Cragoe's methods (Cragoe et al., 1967).
It has been reported that the cell growth of alkalophiles and $V$. parahaemolyticus is not affected by phenamil, even at concentrations that fully block rotation of the flagellar motors (Atsumi et al., 1990, 1992b; Kawagishi et al., 1996). V. alginolyticus cells grew normally in VC medium containing a high concentration $(500 \mu \mathrm{M})$ of phenamil, while motility of the wild-type cells was completely inhibited (data not shown). This indicates that phenamil works as a specific inhibitor of the $\mathrm{Na}^{+}$-motors of $V$. alginolyticus, without affecting cell growth.

$V$. alginolyticus VIO5 ( Pof $^{+}$Laf $^{-}$Rifr $)$cells were treated with ethylmethane sulfonate (EMS) and streaked onto the surface of $0.25 \%$ agar VD plates supplemented with $500 \mu \mathrm{M}$ phenamil, and the plates were incubated. Cells that spread out from the point of inoculation on the plate were isolated, and two isolates were named NMB201 and NMB205. We confirmed the resistant phenotype in a $0.25 \%$ agar VG plate containing $200 \mu \mathrm{M}$ phenamil (Figure 1). Because these mutants and the parent showed very tumble-biased swimming in the presence of inhibitors, it was quite difficult to measure their swimming speed. We therefore isolated smooth swimming (che) mutants, NMB136 (from VIO5), NMB157 (from NMB201), and NMB160 (from NMB205). These che mutants swam at the same swimming speed as the parent strains, and showed the same inhibition profiles against the phenamil concentrations (data not shown). Thus, the motor function seems not to be affected in the che mutants. NMB136 (phenamil-sensitive) and NMB157 (phenamil-resistant) were then characterized more closely. We named the phenotype $\mathrm{Mpa}^{\mathrm{r}}$ for motility resistant to $p$ henamil. Accordingly, the wild-type phenotype was designated as $\mathrm{Mpa}^{\text {s }}$.

\section{Effect of specific inhibitors on the mutants}

We first examined whether the motility of $\mathrm{Mpa}^{\mathrm{r}}$ cells (NMB157) and $\mathrm{Mpa}^{\mathrm{s}}$ cells (NMB136) showed

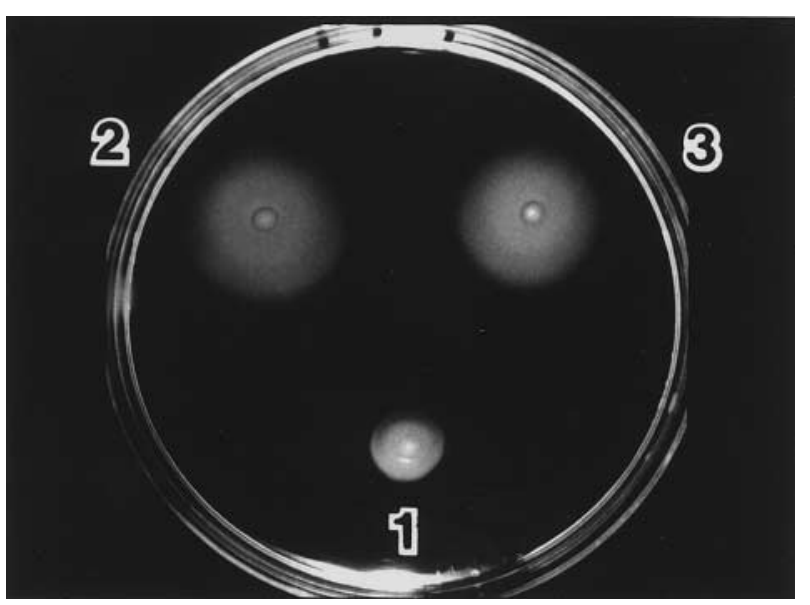

Figure 1. Swarming abilities of the mutants in the presence of phenamil. A VG semi-solid plate containing $200 \mu \mathrm{M}$ phenamil was incubated at $30^{\circ} \mathrm{C}$ for 20 hours. 1, the $\mathrm{Mpa}^{\mathrm{s}}$ parent strain (VIO5); 2 and 3, the $\mathrm{Mpa}^{\mathrm{r}}$ mutants (NMB201 and NMB205). 


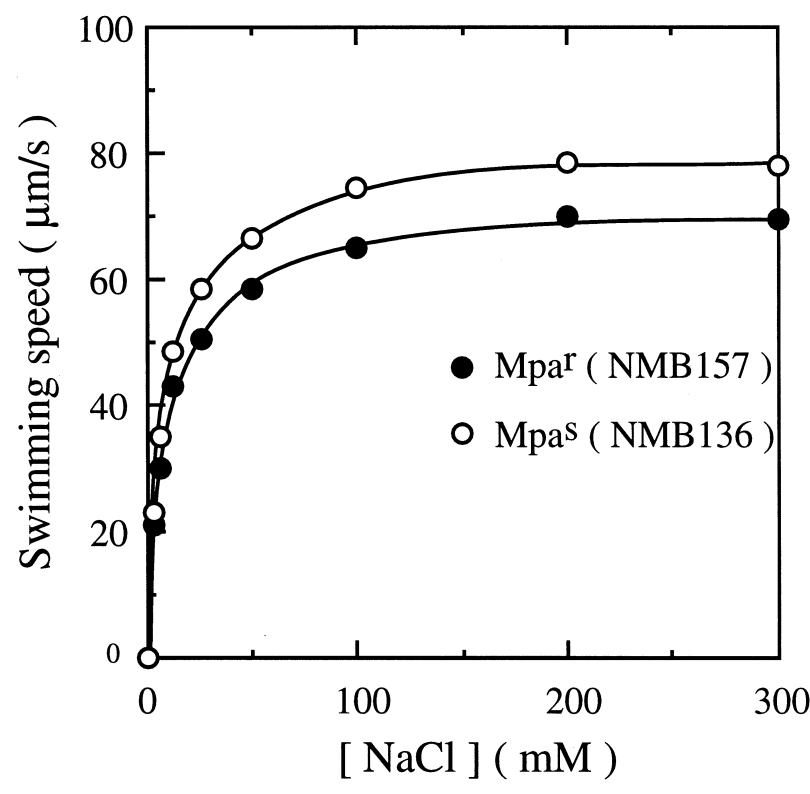

Figure 2. Relationship between $\mathrm{Na}^{+}$concentration of media and swimming speed of $\mathrm{Mpa}^{\mathrm{r}}$ cells. Cells from the $\mathrm{Mpa}^{\mathrm{r}}$ strain (O) or the $\mathrm{Mpa}^{\mathrm{s}}$ strain (O) were harvested at late logarithmic phase and suspended in TNM medium ( $\mathrm{pH}$ 7.5). The cell suspension was diluted about 100 -fold into the TNM medium containing various concentrations of $\mathrm{NaCl}$. Swimming speed was measured within one minute as described in Materials and Methods.

similar dependence on the external $\mathrm{Na}^{+}$concentration. Their motility profiles were indistinguishable, although $\mathrm{Mpa}^{\mathrm{r}}$ cells swam a little slower than $\mathrm{Mpa}^{\mathrm{s}}$ cells (Figure 2). This suggests that the affinity for $\mathrm{Na}^{+}$is not affected by the mutation and the $\mathrm{Na}^{+}$ binding region is essentially unchanged in $\mathrm{Mpa}^{\mathrm{r}}$ cells.

Next, we examined the swimming speed of $\mathrm{Mpa}^{\mathrm{r}}$ cells in various concentrations of phenamil, amiloride or benzamil (Figure 3). The motility of $\mathrm{Mpa}^{\mathrm{s}}$ cells was completely inhibited by $50 \mu \mathrm{M}$ phenamil. In contrast, $\mathrm{Mpa}^{\mathrm{r}}$ cells still swam at $12 \mu \mathrm{m} /$ second and were stopped only by $500 \mu \mathrm{M}$ phenamil. When amiloride was used, differences between $\mathrm{Mpa}^{\mathrm{r}}$ and $\mathrm{Mpa}^{\mathrm{s}}$ cells were less pronounced. $\mathrm{Mpa}^{\mathrm{r}}$ cells swam 20 or $30 \%$ faster than $\mathrm{Mpa}^{\mathrm{s}}$ cells in the range of $0.5 \mathrm{mM}$ to $2.0 \mathrm{mM}$ amiloride. Difference in swimming speed were observed when $\mathrm{Na}^{+}$concentration was varied in the presence of $1 \mathrm{mM}$ amiloride. At lower $\mathrm{Na}^{+}$ concentrations, $\mathrm{Mpa}^{\mathrm{r}}$ cells swam faster than $\mathrm{Mpa}^{\mathrm{s}}$ cells (data not shown). This difference indicates that the mutation affects the amiloride sensitivity of the motor. However, we could not detect any difference between the swarming abilities of $\mathrm{Mpa}^{\mathrm{r}}$ and $\mathrm{Mpa}^{\mathrm{s}}$ strains in a semi-solid plate containing $1 \mathrm{mM}$ amiloride. The inhibition profile by benzamil, whose potency is intermediate between phenamil and amiloride (Sugiyama et al., 1988; Imae., 1991), showed no difference between the $\mathrm{Mpa}^{\mathrm{r}}$ and $\mathrm{Mpa}^{\mathrm{s}}$ strain. These results suggest that the mutation affects mainly the phenamil interaction site in the $\mathrm{Na}^{+}$-driven motor.

To quantify the effect of the mutation on phenamil binding, we estimated the inhibition constant $\left(K_{i}\right)$ in both strains. We measured their swimming speeds in the presence of $6.25,25$, and $100 \mathrm{mM} \mathrm{NaCl}$ under various concentrations of phenamil. Figure 4 is a Dixon plot of the phenamil concentration and the $\mathrm{Na}^{+}$influx estimated from the swimming speed by a kinetic analysis described previously (Sugiyama et al., 1988). This shows that the inhibition profile of phenamil in a $\mathrm{Mpa}^{\mathrm{r}}$ strain changes into a rather competitive manner with $\mathrm{Na}^{+}$. The $K_{i}$ values of the $\mathrm{Mpa}^{\mathrm{s}}$ and $\mathrm{Mpa}^{\mathrm{r}}$ strains were $0.14 \mu \mathrm{M}$ and $0.74 \mu \mathrm{M}$, respectively.

\section{Fluctuation of the rotation rate in the phenamil-resistant mutant}

It has been shown that the rotation rate becomes very unstable in the presence of phenamil but not in the presence of amiloride or $\mathrm{CCCP}$, even when the inhibitors are used at concentrations that reduce the rotation rate by the same amount (Muramoto et al., 1996). We investigated the stability of $\mathrm{Mpa}^{\mathrm{r}}$ flagellar rotation at $50 \mathrm{mM} \mathrm{NaCl}$ in the presence of phenamil and amiloride. The $\mathrm{Mpa}^{\mathrm{r}}$ and $\mathrm{Mpa}^{\mathrm{s}}$ cell bodies were fixed on the glass surface, and the free rotation of a single flagellum was measured by using laser-dark field microscopy (LDM). Figure 5 shows the periodic change in photon counts observed under each condition. When the rotation rate of a $\mathrm{Mpa}^{\mathrm{s}}$ flagellum was decreased to about 200 r.p.s. by $1 \mu \mathrm{M}$ phenamil, large fluctuations in rotation rate were observed (Figure 5(A)). In the case of a $\mathrm{Mpa}^{\mathrm{r}}$ cell, when the rotation rate was decreased to about 200 r.p.s. by $5 \mu \mathrm{M}$ phenamil, the speed fluctuations were significantly smaller than in the $\mathrm{Mpa}^{\mathrm{s}}$ strain (Figure 5(B)). On the other hand, when the rotation rate was decreased to about 200 r.p.s. by $0.5 \mathrm{mM}$ amiloride, both the $\mathrm{Mpa}^{\mathrm{r}}$ and $\mathrm{Mpa}^{\mathrm{s}}$ flagella rotated very smoothly and there was little change of the rotation period, peak-to-peak interval (Figure 5(C) and 5(D)). The fluctuations seen with phenamil in the $\mathrm{Mpa}^{\mathrm{r}}$ strain were still larger than those seen with amiloride.

Rotation rates in the presence of phenamil or amiloride were calculated from the rotation periods and their distribution plotted on histograms (Figure 6). When the rotation rate was reduced by phenamil, the rotation rate of the $\mathrm{Mpa}^{\mathrm{s}}$ flagella fluctuated between 50 and 500 r.p.s., and the slow rotation sometimes persisted for relatively long times (Figure 6(A)). The variation in the rotation period of $\mathrm{Mpa}^{\mathrm{r}}$ flagella was smaller, and periods of slow rotation were shorter (Figure 6(B)). In the presence of amiloride, the rotation rates of both $\mathrm{Mpa}^{\mathrm{r}}$ and $\mathrm{Mpa}^{\mathrm{s}}$ flagella were distributed sharply around the average rotation rate (Figure $6(\mathrm{C})$ and (D)).

To evaluate this difference in various cells, we obtained the standard deviation of the rotation rate $\left(\sigma_{\omega}\right)$ and expressed the fluctuation as $\left(\sigma_{\omega} / \bar{\omega}\right) \times$ 


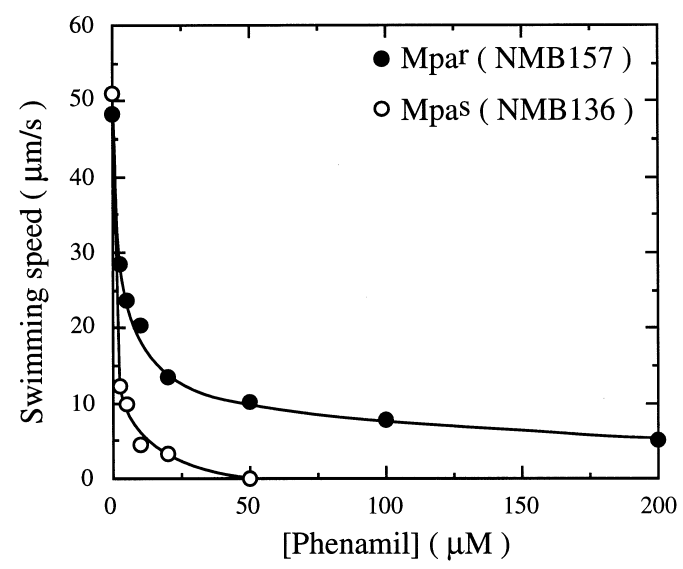

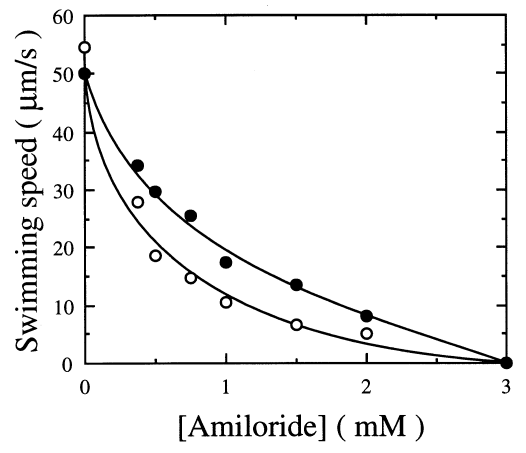

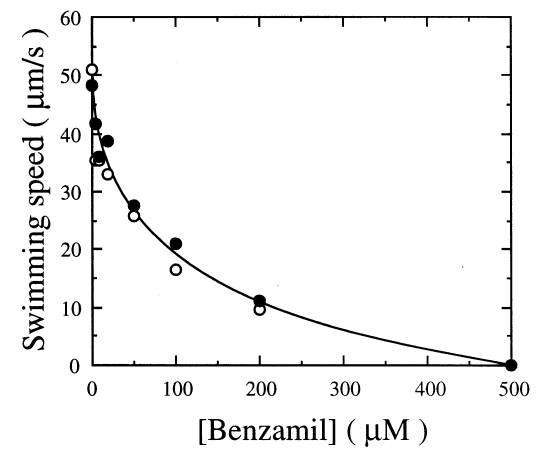

Figure 3. Motility inhibition of $\mathrm{Mpa}^{\mathrm{r}}$ cells by specific inhibitors. Cells of the $\mathrm{Mpa}^{\mathrm{r}}$ strain (O) or the $\mathrm{Mpa}^{\mathrm{s}}$ strain (O) were suspended in TNM medium containing various concentrations of inhibitors, and the swimming speed was measured as described in Materials and Methods.
$100(\%)$. The data obtained from four cells are summarized in Table 1 . In the presence of phenamil, the speed fluctuations of $\mathrm{Mpa}^{\mathrm{s}}$ cells increased to $40 \%$, and in $\mathrm{Mpa}^{\mathrm{r}}$ cells $24 \%$. When we used $0.5 \mathrm{mM}$ amiloride as a control, both $\mathrm{Mpa}^{\mathrm{s}}$ and $\mathrm{Mpa}^{\mathrm{r}}$ strains showed the same fluctuation, about $16 \%$. In the absence of phenamil or amiloride, the motors of $\mathrm{Mpa}^{\mathrm{s}}$ and $\mathrm{Mpa}^{\mathrm{r}}$ strains rotated at 640 and 550 r.p.s., respectively, with fluctuations of $15 \%$ (data not shown). These results indicate that the fluctuations are significantly reduced in the $\mathrm{Mpa}^{\mathrm{r}}$ strain, relative to the wild-type.

\section{Discussion}

To study the $\mathrm{Na}^{+}$-driven motor, we isolated motility mutants resistant to phenamil $\left(\mathrm{Mpa}^{\mathrm{r}}\right)$. Phenamil is the most potent specific inhibitor of a $\mathrm{Na}^{+}$-driven motor and does not severely affect cell growth or physiology. The growth and $\mathrm{Na}^{+}$-dependent motility of the $\mathrm{Mpa}^{\mathrm{r}}$ mutant were the same as those of the parent $\mathrm{Mpa}^{\mathrm{s}}$ strain, which is wild-type as far as the polar flagellum is concerned. The mutant was significantly more resistant to phenamil, exhibiting an inhibition constant about five times larger than that of the $\mathrm{Mpa}^{\mathrm{s}}$ strain. This suggests that the $\mathrm{Mpa}^{\mathrm{r}}$ mutation affects the interaction between phenamil and the motor.

The sensitivity to benzamil was not changed in the mutant and the sensitivity to amiloride was only slightly reduced. These results suggest that the mutation affects mainly the phenamil interaction site in the flagellar motor, and to a lesser extent the amiloride interaction site. In previous work, motility mutants resistant to phenamil were isolated from an alkalophilic Bacillus. These mutants suggested that amiloride and phenamil have different interaction sites in the motor (Atsumi et al., 1990), because the sensitivity to amiloride was not affected. This difference between the two species might reflect differences in the mutations or in the $\mathrm{Na}^{+}$binding regions.

It has been observed that the motor rotation rate fluctuates in the presence of phenamil but not amiloride or CCCP (Muramoto et al., 1996) and it was suggested that this phenomenon is due to the longer duration of phenamil binding to the motor. If there are several force-generating units in one motor and each unit functions independently, then the number of functional units is proportional to the rotation rate and changes in this number cause the fluctuations of rotation rate. In the case of phenamil, since the dissociation rate constant should be small, phenamil binds stably to the motor. So unstable rotation at subnormal speed is detected by LDM. On the other hand, the interaction of amiloride with the force-generating units should be more rapid, and an average speed corresponding to the average number of active force-generating units is detected. The fluctuations of rotation rate, given by the tethering technique, in the $\mathrm{H}^{+}$-motor of $E$. coli were explained by a model incorporating dissociation and association of the force-generating units (Kara-Ivanov et al., 1995). 

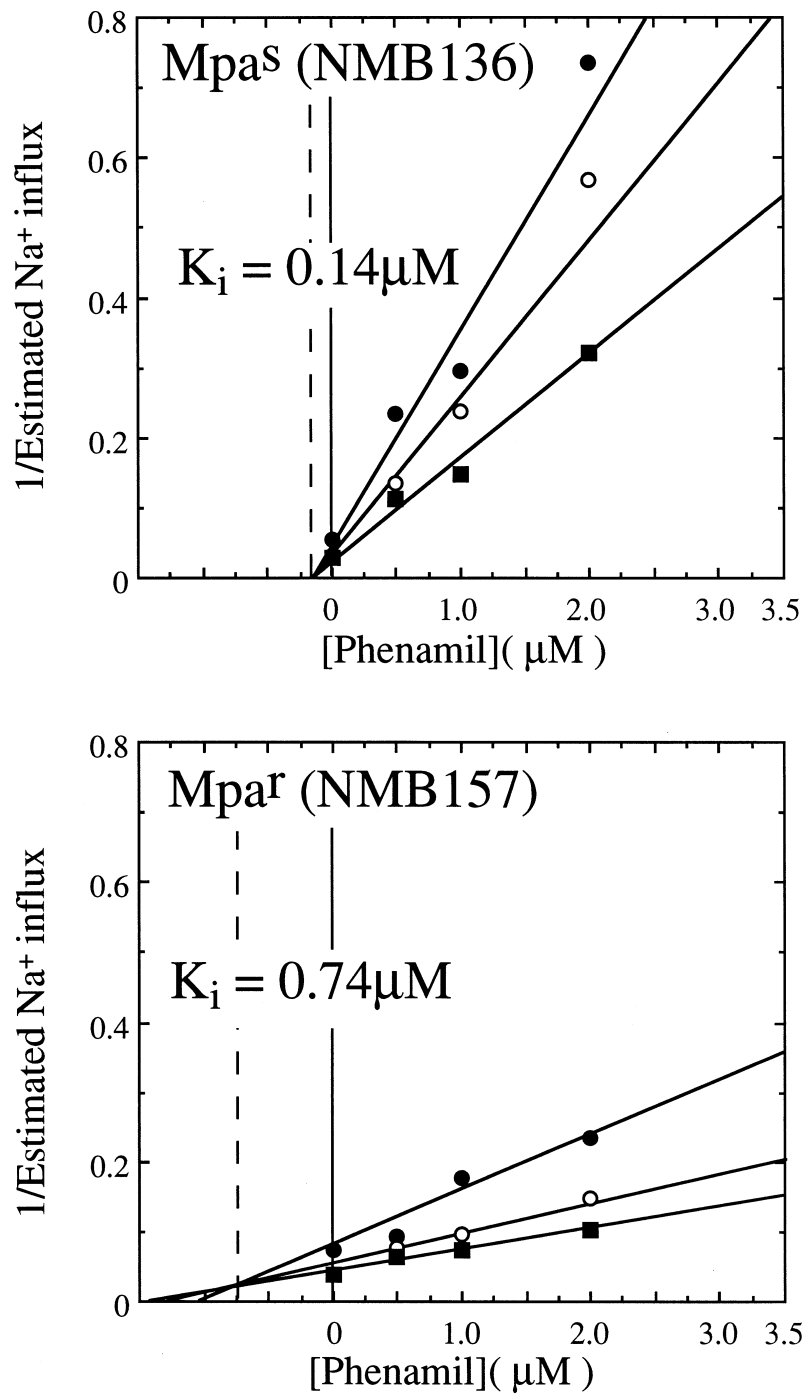

Figure 4. Effect of various concentrations of phenamil on the estimated $\mathrm{Na}^{+}$influx through the motors of $\mathrm{Mpa}^{\mathrm{s}}$ (upper) and $\mathrm{Mpa}^{\mathrm{r}}$ (lower). Cells were suspended in TNM medium containing $6.25 \mathrm{mM}(\mathbf{O}), 25 \mathrm{mM}(\bigcirc)$, or $100 \mathrm{mM}$ (ם) $\mathrm{NaCl}$ and various concentrations of phenamil were added. The swimming speed was measured as described in Materials and Methods and the $\mathrm{Na}^{+}$influx was estimated as described previously (Sugiyama et al., 1988). The sodium motive force was calculated by using the membrane potential of $-110 \mathrm{mV}$ and the intracellar $\mathrm{Na}^{+}$ of $50 \mathrm{mM}$ (Tokuda et al., 1988). A reciprocal plot (Dixon plot) of those data was performed. The units in the ordinate are given as $\mathrm{mV} \mathrm{s}^{2} \mu \mathrm{m}^{-2}$.

The model is essentially the same as our model though the time resolution is extremely different.

The phenamil resistance of the mutant isolated in this work can be explained by an increase in the dissociation rate of phenamil, a decrease in the association rate, or both. If the dissociation rate increases, the binding time of phenamil will be shorter, reducing the amplitude of the speed fluctuations. If the association rate decreases, then the binding time should not change, and fluctuation would not be affected. The LDM analysis indicates
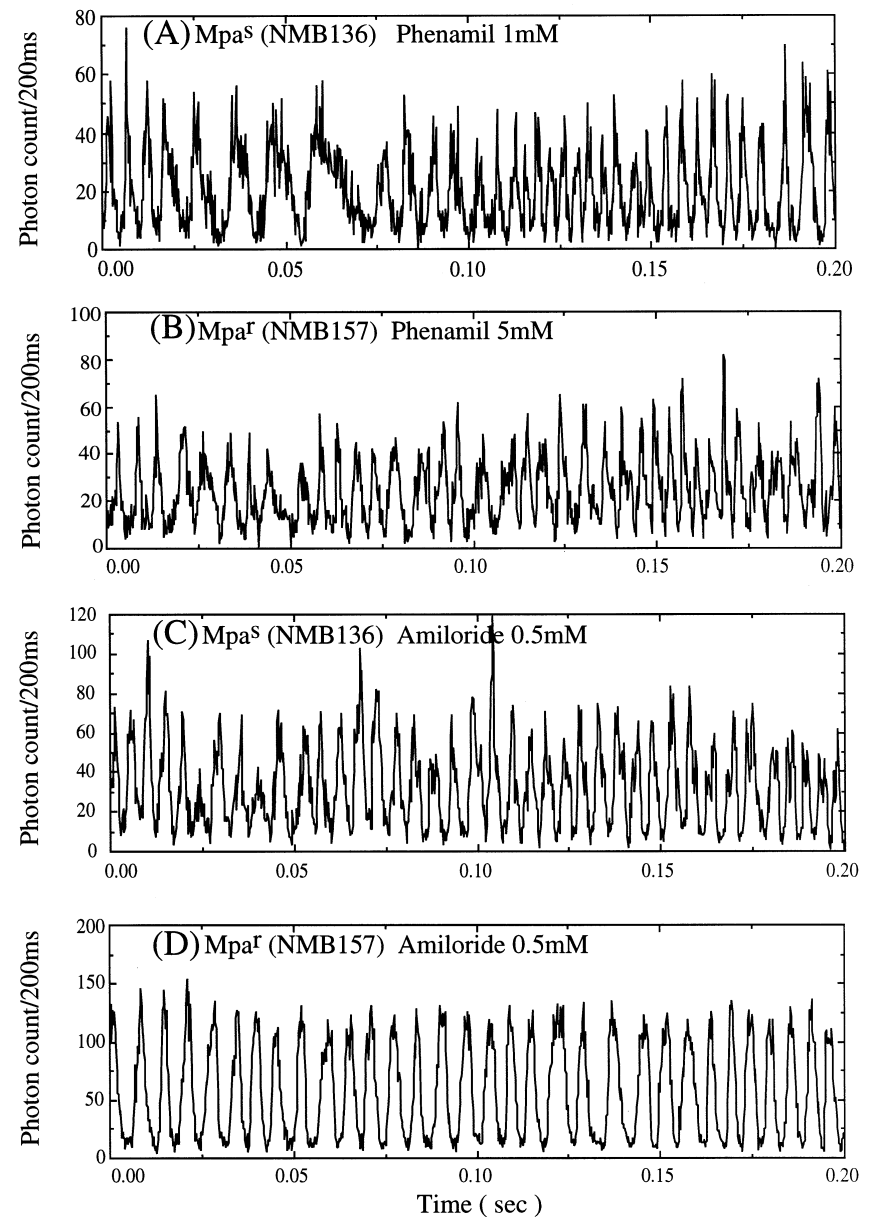

Figure 5. $\mathrm{Mpa}^{\mathrm{s}}$ and $\mathrm{Mpa}^{\mathrm{r}}$ flagellar rotation detected by LDM. Peak intervals of the intensity changes of the scattered light from the rotating flagella correspond to the rotation period. Cells harvested at late logarithmic phase were stuck on the cover glass and the rotation of single flagella were measured by LDM for about six seconds in the presence of phenamil or amiloride which decrease the rotation rate to about 200 r.p.s. (A) The $\mathrm{Mpa}^{\mathrm{s}}$ flagella with $1 \mu \mathrm{M}$ phenamil; (B) the $\mathrm{Mpa}^{\mathrm{r}}$ flagella with $5 \mu \mathrm{M}$ phenamil; (C) the $\mathrm{Mpa}^{\mathrm{s}}$ flagella with $0.5 \mathrm{mM}$ amiloride; (D) the $\mathrm{Mpa}^{\mathrm{r}}$ flagella with $0.5 \mathrm{mM}$ amiloride.

that the $\mathrm{Mpa}^{\mathrm{r}}$ strain shows significantly smaller fluctuations than the $\mathrm{Mpa}^{\mathrm{s}}$ strain. Accordingly, we suggest that phenamil may dissociate from the motor faster in the mutant and this causes the resistance to phenamil.

The interaction of phenamil and amiloride with the motor is speculated as follows. Amiloride is suggested to associate with the same site in the motor as do sodium ions, and quickly associate and dissociate with the motor, causing the competitive inhibition with $\mathrm{Na}^{+}$. On the other hand, phenamil is assumed to interact at another high affinity site and can bind more stably to the motor than amiloride, causing the non-competitive inhibition with $\mathrm{Na}^{+}$. Moreover, phenamil can also associate with the amiloride binding site because of structural similarity. In the $\mathrm{Mpa}^{\mathrm{r}}$ motor, we think that the high affinity site for phenamil is mutated, 

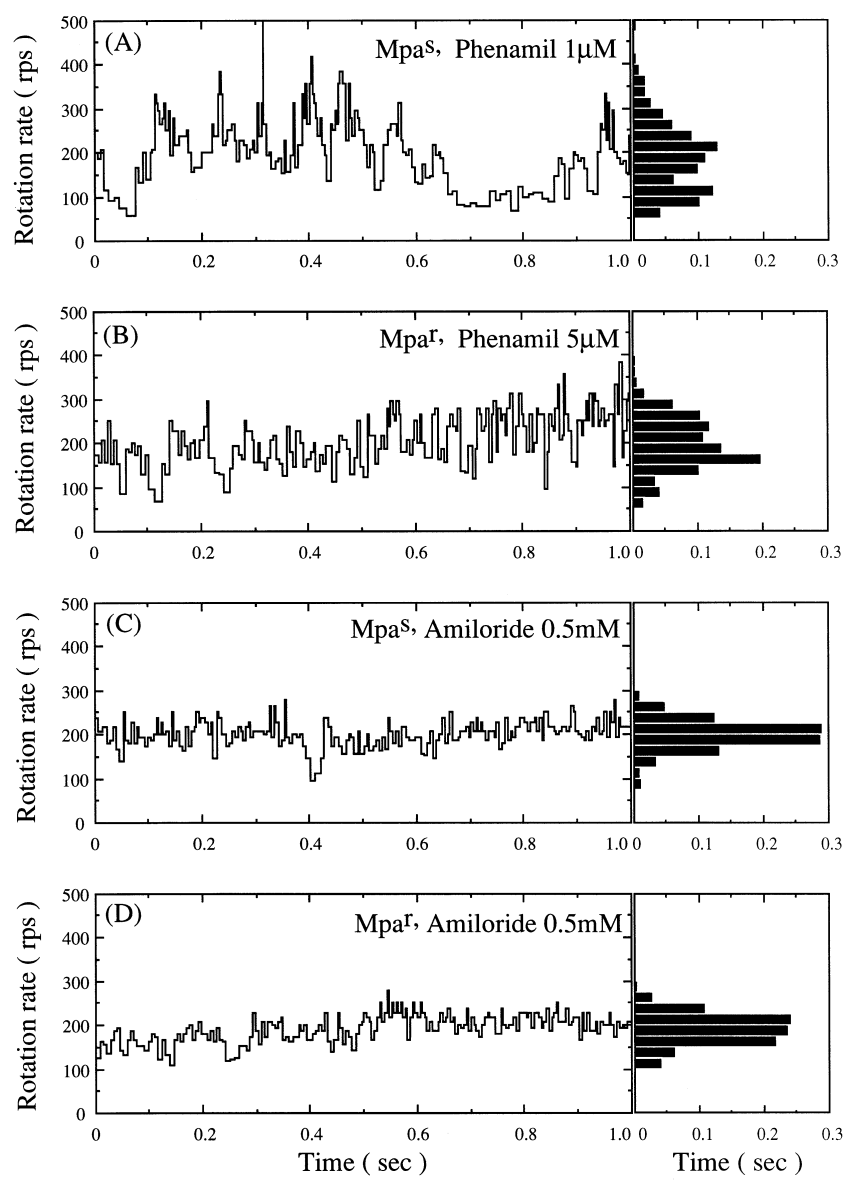

Figure 6. The rotation rate and its distribution of the $\mathrm{Mpa}^{\mathrm{s}}$ and $\mathrm{Mpa}^{\mathrm{r}}$ flagella in the presence of phenamil and amiloride. The rotation rate calculated from the data of Figure 5 for one second as described in Materials and Methods was shown in the left graphs. Histogram of rotation rate for one second was shown in the right graphs. (A) The Mpas flagella with $1 \mu \mathrm{M}$ phenamil; (B) the $\mathrm{Mpa}^{\mathrm{r}}$ flagella with $5 \mu \mathrm{M}$ phenamil; (C) the $\mathrm{Mpa}^{\mathrm{s}}$ flagella with $0.5 \mathrm{mM}$ amiloride; (D) the $\mathrm{Mpa}^{\mathrm{r}}$ flagella with $0.5 \mathrm{mM}$ amiloride. Average rotation rate $(\omega)$ was 182 r.p.s. (A), 194 r.p.s. (B), 198 r.p.s. (C),188 r.p.s. (D). The values of the fluctuation were $42 \%$ (A), $29 \%$ (B), $15 \%$ (C), $17 \%(\mathrm{D})$.

so phenamil additionally interacts with the amiloride binding site, causing phenamil to dissociate more rapidly than in the $\mathrm{Mpa}^{\mathrm{s}}$ motor and the intermediate inhibition profile between amiloride and phenamil. The mutation might also cause subtle structural changes around the common interaction site, because inhibition by amiloride was also slightly affected by the mutation. Benzamil, which is larger than phenamil, can slightly interact with the high affinity site for phenamil and the mutation may not greatly affect their inhibition profile.

The interaction between amiloride analogs and their targets has been studied in various $\mathrm{Na}^{+}$-transporters and with anti-amiloride antibodies (Cragoe et al., 1992; Lin et al., 1994). In the fibroblast $\mathrm{Na}^{+} / \mathrm{H}^{+}$ exchanger (NHE1), which has ten transmembrane segments, a mutant resistant to amiloride was isolated (Counillon et al., 1993). This mutant has point mutations that convert Phe165 and Phe168 into Tyr. These residues are located in the middle of the fourth putative transmembrane segment. However, in the case of the epithelial $\mathrm{Na}^{+}$channel (ENAC), which is supposed to have six transmembrane segments, a recent report suggested that the amiloride-binding site resides on an extracellular loop of the $\alpha$ subunit and not the putative second transmembrane domain which forms a channel pore ( $\mathrm{Li}$ et al., 1995). The amiloride-binding site may therefore be in very different locations in different proteins, although an additional possibility that the mutations in $\mathrm{Na}^{+} / \mathrm{H}^{+}$exchanger mapped in membrane segments might cause a change in conformation that affects an extracellular binding site for amiloride cannot be eliminated. It is also known that phenamil is a more potent inhibitor of the $\mathrm{Na}^{+}$channel than the $\mathrm{Na}^{+} / \mathrm{H}^{+}$ exchanger (Cragoe et al., 1992). Since the $\mathrm{Na}^{+}-$ driven motor is also inhibited potently by phenamil, it might have more features in common with the $\mathrm{Na}^{+}$channel. However, the additional high affinity binding site of phenamil in the scheme described above has not yet been identified in the $\mathrm{Na}^{+}$channel.

Recently, the mot $X$ and mot $Y$ genes, which seem to encode components of the force-generating units, were isolated from Vibrio parahaemolyticus (McCarter, 1994a,b). MotX is inferred to be a component of the $\mathrm{Na}^{+}$channel of the motor because overproduction of MotX was lethal in E. coli in proportion to the external $\mathrm{Na}^{+}$concentration, but this effect was suppressed by the addition of amiloride. The C-terminal domain of MotY is homologous to many peptidoglycan-interacting proteins. So, MotX and MotY, each of which has a putative single transmembrane region, form a channel component and a stator component, respectively, as the $\mathrm{H}^{+}$motor components of MotA and MotB (Blair, 1995). The pom (polar flagella motility) genes, whose mutants have paralysed polar flagella, identical to $\operatorname{mot} X$ and $\operatorname{mot} Y$, were detected in $V$. alginolyticus (Okunishi et al., 1996) and novel pom genes have been isolated (Asai, Y., Okunishi, I., Kojima, S., Kawagishi, I. \& Homma, M., unpublished). We expected that the $\mathrm{Mpa}^{\mathrm{r}}$ mutation would map to one of the genes coding for the motor proteins, or to other components of the force-generating units. Actually, the $\mathrm{Mpa}^{\mathrm{r}}$ mutation was mapped in a pom gene other than mot $X$ and mot $Y$ genes (Kojima, S., Asai, Y., Kawagishi, I. \& Homma, M., unpublished). We hope to determine the target of phenamil and thereby obtain information about the mechanism by which $\mathrm{Na}^{+}$is used to drive the motor.

\section{Materials and Methods}

\section{Bacterial strains, growth conditions and media}

$V$. alginolyticus VIO5 (Okunishi et al., 1996) was used as the parent strain to isolate mutants. It is a Pof $^{+}$Laf $^{-}$Rif $^{r}$ 
Table 1. Summary of the results of effect of phenamil and amiloride on the stability of rotation rate of $\mathrm{Mpa}^{\mathrm{r}}$ and $\mathrm{Mpa}^{\mathrm{s}}$ strains obtained from four independent cells

\begin{tabular}{llrrrrr}
\hline & & 1 & 2 & 3 & 4 & Average \\
\hline $\mathrm{Mpa}^{\mathrm{s}}$ (NMB136) & Rotation rate (r.p.s.) & 197 & 207 & 131 & 182 & 179 \\
$1 \mu \mathrm{M}$ Phenamil & Standard deviation (r.p.s.) & 79 & 79 & 51 & 77 & 72 \\
& Fluctuation (\%) & 40 & 38 & 39 & 42 & 40 \\
$\mathrm{Mpa}^{\mathrm{r}}$ (NMB157) & Rotation rate (r.p.s.) & 170 & 221 & 160 & 194 & 186 \\
$5 \mu \mathrm{M} \mathrm{Phenamil}$ & Standard deviation (r.p.s.) & 47 & 42 & 34 & 57 & 45 \\
& Fluctuation (\%) & 28 & 19 & 21 & 29 & 24 \\
$\mathrm{Mpa}^{\mathrm{s}}$ (NMB136) & Rotation rate (r.p.s.) & 198 & 138 & 162 & 158 & 164 \\
$0.5 \mathrm{mM} \mathrm{Amiloride}$ & Standard deviation (r.p.s.) & 30 & 23 & 20 & 19 & 23 \\
$\mathrm{Mpa}^{\mathrm{r}}$ (NMB157) & Fluctuation (\%) & 15 & 17 & 12 & 12 & 14 \\
$0.5 \mathrm{mM} \mathrm{Amiloride}$ & Rotation rate (r.p.s.) & 188 & 270 & 258 & 258 & 243 \\
& Standard deviation (r.p.s.) & 32 & 30 & 29 & 33 & 31 \\
\hline
\end{tabular}

strain derived from strain VIK4 (Okunishi et al., 1996), which is a rifampicin-resistant derivative of the wild-type strain 138-2 (Tokuda et al., 1988).

Cells were grown at $30^{\circ} \mathrm{C}$ with shaking in VG medium containing $1 \%(\mathrm{w} / \mathrm{v})$ polypeptone, $0.5 \%(\mathrm{w} / \mathrm{v})$ glycerol, $0.4 \%(\mathrm{w} / \mathrm{v}) \mathrm{K}_{2} \mathrm{HPO}_{4}$, and $0.5 \mathrm{M} \mathrm{NaCl}$. To select motility mutants, $0.25 \%(\mathrm{w} / \mathrm{v})$ agar VD plates $(0.25 \%$ agar in VD medium containing $0.5 \%$ polypeptone, $0.2 \%$ glucose, $0.5 \%$ yeast extract, $0.4 \% \mathrm{~K}_{2} \mathrm{HPO}_{4}, 50 \mathrm{mM} \mathrm{NaCl}$, and $250 \mathrm{mM} \mathrm{KCl}$ ) were used.

Vibrio buffer containing $10 \mathrm{mM}$ Tris- $\mathrm{HCl}$ ( $\mathrm{pH}$ 7.0), $10 \mathrm{mM} \mathrm{MgCl}, 350 \mathrm{mM} \mathrm{NaCl}$ was used to wash the cells and TNM medium containing $50 \mathrm{mM}$ Tris- $\mathrm{HCl}$ ( $\mathrm{pH} 7.5$ ), $5 \mathrm{mM} \mathrm{MgCl}_{2}, 5 \mathrm{mM}$ glucose, $50 \mathrm{mM} \mathrm{NaCl}$, $250 \mathrm{mM} \mathrm{KCl}$ was used to measure the swimming speed. When the concentration of $\mathrm{Na}^{+}$in the motility medium was varied, $\mathrm{KCl}$ was added to keep the salt concentration constant.

\section{Chemicals and anti-flagellar antibody}

Amiloride and benzamil was purchased from Sigma Chemical Co. and Research Biochemical Incorporated, respectively. Phenamil, which was not commercially available, was synthesized by the method of Cragoe et al. (1967).

Anti-polar flagellar antibody was prepared by injecting a rabbit with purified polar flagella of $V$. alginolyticus strain YM4 ( Pof $^{+}$Laf $^{-}$) whose parent is the same as VIO5 (Kawagishi et al., 1995).

\section{Isolation of motility mutants}

Mutagenesis was carried out by using ethyl methanesulfonate (EMS). Cells of VIO5 were harvested by centrifugation from $1.0 \mathrm{ml}$ culture at late logarithmic phase, washed once with Vibrio buffer, and resuspended in $0.5 \mathrm{ml}$ of Vibrio buffer. Then, $15 \mu \mathrm{l}$ of EMS was added to the suspension and incubated with mild shaking for one hour at $30^{\circ} \mathrm{C}$. After washing the cells once with Vibrio buffer, they were resuspended in $0.5 \mathrm{ml}$ of Vibrio buffer. EMS-treated cells were streaked onto the surface of a $0.25 \%$ agar VD plate supplemented with $500 \mu \mathrm{M}$ phenamil, and the plate was incubated at $30^{\circ} \mathrm{C}$ for 12 hours. Mutants that spread out from the point of inoculation were isolated. Phenamil-resistant candidates were tested for rifampicin resistance and also for reactivity to the anti-polar flagellar antibody.

Smooth swimming mutants were isolated from the phenamil-resistant mutants to easily measure their swimming speeds. The che mutants were selected as described previously (Homma et al., 1996).

\section{Measurement of swimming speed}

Cells were harvested at late logarithmic phase and resuspended in TNM medium at half the original culture volume. Then a small amount of the cell suspension was diluted about 100-fold into TNM medium, and motility of the cells was observed under a dark-field microscope and recorded on video tape. Swimming speed was determined as described previously (Atsumi et al., 1996). The average swimming speed was obtained by measuring more than 20 swimming tracks.

\section{Measurement and analysis of single flagellar rotation}

High speed flagellar rotation was measured by laser-dark field microscopy (LDM) as described previously (Kudo et al., 1990; Muramoto et al., 1995). Cells were harvested at late logarithmic phase, washed once with TNM medium, and resuspended in the same medium. The cell suspension was poured into the space between slide and cover glass on which thin spacers were placed. After ten minutes, cells not stuck to the slide were washed by the flow of TNM medium. Rotation of the polar flagellum of a stuck cell was measured by using LDM for about six seconds. When the effect of inhibitor was measured, the stuck cells were washed with the flow of TNM medium supplemented with a suitable amount of inhibitor.

The photon counting gate time was set at $200 \mu \mathrm{s}$. The rotation rate was calculated as a reciprocal of the period of peak intervals, and average rotation rate $(\bar{\omega})$ and its standard deviation $\left(\sigma_{\omega}\right)$ for one second were calculated by the following equations (Muramoto et al., 1996).

$$
\begin{gathered}
\bar{\omega}=\frac{\sum_{k=1}^{N} \omega(k) \tau(k)}{\sum_{k=1}^{N} \tau(k)}=\frac{N}{t_{0}} \\
\sigma_{\omega}=\sqrt{\frac{\sum_{k=1}^{N}(\omega(k)-\bar{\omega})^{2} \tau(k)}{\sum_{k=1}^{N} \tau(k)} .}
\end{gathered}
$$


Here, $\omega(k)$ and $\tau(k)$ are the rotation rate and period for $k$ th revolution, $t_{0}$ is the duration of measurement, $N$ is the total number of revolutions.

\section{Acknowledgements}

We thank Dr Robert M. Macnab for invaluable discussions and Dr Kohtaro Tomizawa for assistance with the phenamil synthesis. We especially thank Dr David F. Blair for critical reading of the manuscript. This work was supported in part by grants-in-aid for scientific researches (to T.A., I.K. and M.H.) from the Ministry of Education, Science and Culture of Japan and by $\mathrm{R} \& \mathrm{D}$ program from NEDO of Japan (to I.K. and M.H.).

\section{References}

Allen, R. D. \& Baumann, P. (1971). Structure and arrangement of flagella in species of the genus Beneckea and Photobacterium fischeri. J. Bacteriol. 107, 295-302.

Atsumi, T., Sugiyama, S., Cragoe, E. J., Jr \& Imae, Y. (1990). Specific inhibition of the $\mathrm{Na}^{+}$-driven flagellar motors of alkalophilic Bacillus strains by the amiloride analog phenamil. J. Bacteriol. 172, 16341639.

Atsumi, T., McCarter, L. \& Imae, Y. (1992a). Polar and lateral flagellar motors of marine Vibrio are driven by different ion-motive forces. Nature, 355, 182-184.

Atsumi, T., Maekawa, Y., Tokuda, H. \& Imae, Y. (1992b). Amiloride at $\mathrm{pH} 7.0$ inhibits the $\mathrm{Na}^{+}$-driven flagellar motors of Vibrio alginolyticus but allows the cell growth. FEBS Letters, 314, 114-116.

Atsumi, T., Maekawa, Y., Yamada, T., Kawagishi, I., Imae, Y. \& Homma, M. (1996). Effect of viscosity on swimming by the lateral and polar flagella of Vibrio alginolyticus. J. Bacteriol. 178, 5024-5026.

Blair, D. F. (1995). How bacteria sense and swim. Annu. Rev. Microbiol. 49, 489-522.

Blair, D. F. \& Berg, H. C. (1988). Restoration of torque in defective flagellar motors. Science, 242, 16781681.

Block, S. M. \& Berg, H. C. (1984). Successive incorporation of force-generating units in the bacterial rotary motor. Nature, 309, 470-472.

Counillon, L., Franchi, A. \& Pouyssegur, J. (1993). A point mutation of the $\mathrm{Na}^{+} / \mathrm{H}^{+}$exchanger gene (NHE1) and amplification of the mutated allele confer amiloride resistance upon chronic acidosis. Proc. Natl Acad. Sci. USA, 90, 4508-4512.

Cragoe, E. J., Jr, Woltersdorf, O. W., Jr., Bicking, J. B., Kwong, S. F. \& Jones, J. H. (1967). Pyrazine diuretics. II. N-amidino-3-amino-5-substituted 6-halopyrazinecarboxamides. J. Med. Chem. 10, 66-75.

Cragoe, E. J., Jr, Kleyman, T. R. \& Simchowitz, L. (1992). Amiloride and its Analogs: Unique Cation Transport Inhibitors. VCH Publishers, Inc., New York.

Follett, E. A. C. \& Gordon, J. (1963). An electron microscope study of Vibrio flagella. J. Gen. Microbiol. 32, 235-239.

Homma, M., Oota, H., Kojima, S., Kawagishi, I. \& Imae, Y. (1996). Chemotactic responses to an attractant and a repellent in the flagellar systems of Vibrio alginolyticus. Microbiology, 146, 2777-2783.

Imae, Y. (1991). Use of $\mathrm{Na}^{+}$as an alternative to $\mathrm{H}^{+}$in energy transduction. In New Era of Bioenergetics (Mukohata, Y., ed.), pp. 197-221. Academic Press, Inc., Tokyo.

Imae, Y. \& Atsumi, T. (1989). $\mathrm{Na}^{+}$-driven bacterial flagellar motors. J. Bioenerg. Biomemb. 21, 705-716.

Kami-ike, N., Kudo, S., \& Hotani, H. (1991). Rapid changes in flagellar rotation induced by external electric pulses. Biophys. J. 60, 1350-1355.

Kara-Ivanov, M., Eisenbach, M. \& Caplan, S. R. (1995). Fluctuations in rotation rate of the flagellar motor of Escherichia coli. Biophys. J. 69, 250-263.

Kawagishi, I., Maekawa, Y., Atsumi, T., Homma, M. \& Imae, Y. (1995). Isolation of the polar and lateral flagellum-defective mutants in Vibrio alginolyticus and identification of their flagellar driving energy sources. J. Bacteriol. 177, 5158-5160.

Kawagishi, I., Imagawa, M., Imae, Y., McCarter, L. \& Homma, M. (1996). The sodium-driven polar flagellar motor of marine Vibrio as the mechanosensor that regulates lateral flagellar expression. Mol. Microbiol. 20, 693-699.

Kudo, S., Magariyama, Y. \& Aizawa, S.-I. (1990). Abrupt changes in flagellar rotation observed by laser dark-field microscopy. Nature, 346, 677-680.

Li, X. J., Xu, R. H., Guggino, W. B. \& Snyder, S. H. (1995). Alternatively spliced forms of the $\alpha$ subunit of the epithelial sodium channel: distinct sites for amiloride binding and channel pore. Mol. Pharmacol. 47, 1133-1140

Lin, C., Kieber-Emmons, T., Villalobos, A. P., Foster, M. H., Wahlgren, C. \& Kleyman, T. R. (1994). Topology of an amiloride-binding protein. J. Biol. Chem. 269, 2805-2813.

Magariyama, Y., Sugiyama, S., Muramoto, K., Maekawa, Y., Kawagishi, I., Imae, Y. \& Kudo, S. (1994). Very fast flagellar rotation. Nature, 371, 752.

Magariyama, Y., Sugiyama, S., Muramoto, K., Kawagishi, I., Imae, Y. \& Kudo, S. (1995). Simultaneous measurement of bacterial flagellar rotation rate and swimming speed. Biophys. J. 69, 2154-2162.

McCarter, L. L. (1994a). MotY, a component of the sodium-type flagellar motor. J. Bacteriol. 176, 4219-4225.

McCarter, L. L. (1994b). MotX, the channel component of the sodium-type flagellar motor. J. Bacteriol. 176, 5988-5998.

McCarter, L., Hilmen, M. \& Silverman, M. (1988). Flagellar dynamometer controls swarmer cell differentiation of V. parahaemolyticus. Cell, 54, 343-351.

Muramoto, K., Sugiyama, S., Cragoe, E. J., Jr \& Imae, Y. (1994). Successive inactivation of the force-generating units of sodium-driven bacterial flagellar motors by a photoreactive amiloride analog. J. Biol. Chem. 269, 3374-3380.

Muramoto, K., Kawagishi, I., Kudo, S., Magariyama, Y., Imae, Y. \& Homma, M. (1995). High speed rotation and speed stability of the sodium-driven flagellar motor in Vibrio alginolyticus. J. Mol. Biol. 251, 50-58.

Muramoto, K., Magariyama, Y., Homma, M., Kawagishi, I., Sugiyama, S., Imae, Y. \& Kudo, S. (1996). Rotational fluctuation of the sodium-driven flagellar motor of Vibrio alginolyticus induced by binding of inhibitors. J. Mol. Biol. 259, 687-695.

Okunishi, I., Kawagishi, I. \& Homma, M. (1996). Cloning and characterization of $\operatorname{mot} Y$, a gene coding for a component of the sodium-driven flagellar motor in Vibrio alginolyticus. J. Bacteriol. 178, 2409-2415. 
Sugiyama, S., Cragoe, E. J., Jr \& Imae, Y. (1988). Amiloride, a specific inhibitor for the $\mathrm{Na}^{+}$-driven flagellar motors of alkalophilic Bacillus. J. Biol. Chem. 263, 8215-8219.
Tokuda, H., Asano, M., Shimamura, Y., Unemoto, T., Sugiyama, S. \& Imae, Y. (1988). Roles of the respiratory $\mathrm{Na}^{+}$pump in bioenergetics of Vibrio alginolyticus. J. Biochem. 103, 650-655.

Edited by J. Karn

(Received 5 July 1996; received in revised form 21 October 1996; accepted 28 October 1996) 